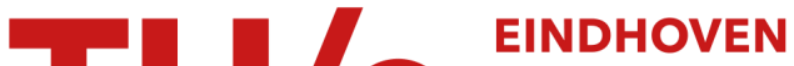 UNIVERSITY OF TECHNOLOGY
}

\section{State Estimator Design for Real-time Controlled Restraint Systems}

\section{Citation for published version (APA):}

Laan, van der, E. P., Veldpaus, F. E., van Schie, C., \& Steinbuch, M. (2007). State Estimator Design for Realtime Controlled Restraint Systems. In Proceedings of the 2007 American Control Conference (ACC 2007) 9-13 July 2007, New York, New York, USA (pp. 242-247). Institute of Electrical and Electronics Engineers. https://doi.org/10.1109/ACC.2007.4282870

DOI:

10.1109/ACC. 2007.4282870

Document status and date:

Published: 01/01/2007

\section{Document Version:}

Publisher's PDF, also known as Version of Record (includes final page, issue and volume numbers)

\section{Please check the document version of this publication:}

- A submitted manuscript is the version of the article upon submission and before peer-review. There can be important differences between the submitted version and the official published version of record. People interested in the research are advised to contact the author for the final version of the publication, or visit the $\mathrm{DOI}$ to the publisher's website.

- The final author version and the galley proof are versions of the publication after peer review.

- The final published version features the final layout of the paper including the volume, issue and page numbers.

Link to publication

\section{General rights}

Copyright and moral rights for the publications made accessible in the public portal are retained by the authors and/or other copyright owners and it is a condition of accessing publications that users recognise and abide by the legal requirements associated with these rights.

- Users may download and print one copy of any publication from the public portal for the purpose of private study or research.

- You may not further distribute the material or use it for any profit-making activity or commercial gain

- You may freely distribute the URL identifying the publication in the public portal.

If the publication is distributed under the terms of Article 25fa of the Dutch Copyright Act, indicated by the "Taverne" license above, please follow below link for the End User Agreement:

www.tue.nl/taverne

Take down policy

If you believe that this document breaches copyright please contact us at:

openaccess@tue.nl

providing details and we will investigate your claim. 


\title{
State Estimator Design for Real-time Controlled Restraint Systems
}

\author{
Ewout van der Laan, Frans Veldpaus, Cees van Schie and Maarten Steinbuch
}

\begin{abstract}
In this paper, a method is presented to estimate the motion of a vehicle occupant in frontal impact. Knowledge of the occupant's motion during a crash can significantly reduce the risk of injury, as restraint systems could be real-time adapted to the optimal settings. It is shown that the chest acceleration of the occupant, an important measure of injury, is accurately estimated by filtering of the belt displacement at the retractor side. Low order, nonlinear models are constructed from complex models, and a state estimator filter is designed using a linearization of these low order models.
\end{abstract}

\section{INTRODUCTION}

\section{A. Background}

In the field of automotive engineering, restraint systems refer to the safety devices in a vehicle that assist in restraining the occupant during a crash. Today's restraint systems typically include a number of airbags, and a three-point seat belt with load limiter and pretensioner. The design and development of these safety devices is largely oriented towards car occupants of average height and weight for a set of standardized, high speed crashes. In general, restraint systems are not able to adjust their performance characteristics during a crash event, and an occupant that deviates from the average will thus not be optimally protected in every crash. To still achieve a satisfactory performance in all scenarios, the restraint design is a tradeoff.

Occupant safety is greatly improved by adaptive restraint systems. Although the terminology on restraint systems found in literature is not consistent, in this paper, adaptive refers to the fact that the restraint characteristics are set before the restraint is effective (during or before the crash). Current state-of-the-art restraint systems are adaptive, e.g. the dual depth airbag [1], in which one or both chambers are filled based on the crash situation, and the smart airbag [2], which accounts for out-of-position occupants.

Adaptive restraint systems generally adapt only once to the present crash conditions, such as vehicle closing speed, occupant type, occupant out-of-position and crash type. Consequently, these adaptive systems are still not optimal as they do not actively react to the occupant responses at each time instance. A huge step in injury reduction can be made when the restraint systems are continuously manipulated as a function of a measured signal [3]. In that case they are referred to as real-time controlled active restraint systems and are preferable by far, since they will result in a minimal

This work is supported by TNO in the Netherlands.

Ewout van der Laan, Maarten Steinbuch and Frans Veldpaus are with the Faculty of Mechanical Engineering, Department of Control Systems Technology, Technische Universiteit Eindhoven. E.P.v.d.laan@tue.nl.

Cees van Schie is with TASS (TNO Automotive Safety Solutions), a wholly owned subsidiary of TNO. risk of injury. These kind of systems do not yet exist in today's passenger vehicles, but numerical simulations with a controlled seat-belt and airbag [4], [5] show a significant injury reduction. Therefore, this class of systems should be a main focus of future restraint system development.

\section{B. Problem definition}

There is a number of issues that need to be solved before the next generation passenger vehicles can be equipped with a controlled restraint system. Important problems concern (i) the required restraint actuators, (ii) the sensors to determine the the biomechanical responses, such as head acceleration, chest compression or knee impacts and (iii) the development of control algorithms, which have to deal with different crash scenarios, crash severities and occupant variability.

Firstly, in high speed, frontal crashes - which have the highest percentage of occurrence $(>50 \%)$ compared to rollover, side and rear impacts - the chest is the most affected body region [6]. According to the EuroNCAP frontal protocol [7], the most important chest related injury criteria are the $3 \mathrm{~ms}$ and peak resultant chest acceleration, and the peak chest deflection. Although these injury criteria are based on chest compression and chest acceleration, the latter is chosen as the biomechanical response to be controlled. It is wellknown that the belt force magnitude significantly influences thoracic injuries, e.g. [8]. Since suitable restraint actuators are still under development, it is assumed that an actuator exists that is able to manipulate the force. The airbag only influences the biomechanical responses in the second half of the crash, and its function is more related to head than chest acceleration. It is therefore, in this research, omitted as a restraint system.

Secondly, not all of the required sensors to measure the occupant's movement do yet exist, whereas many of the available sensors are too expensive, too inaccurate or have too low a bandwidth [9]. So automotive safety engineering will largely benefit from alternative techniques in spatial occupant sensing. It is proposed in this paper that filtering of an observable output could help in the estimation of biomechanical responses. In case of the chest acceleration, it is expected that the displacement of the belt at the retractor side could serve as an observable output.

Summarizing, this study aims at the development of realtime controlled restraint systems. This control system has to minimize a chest injury criterium in a frontal vehicle crash of a belt force manipulator. To this end, the chest acceleration, referred to as $a_{\text {chest }}$, is estimated by filtering the belt displacement, referred to as $x_{\text {belt }}$. 


\section{Vehicle occupant models}

The design of a control system usually involves the formulation of low order, preferably linear, models. They have to describe the most important dynamics of the system, here consisting of the occupant, the restraint system components and the vehicle interior. These models can be derived by first-principles modeling, from analyzing input-output data or from a combination of both. The first method is favorable here, since physical models provide insight in the interaction between occupant and restraint system. Furthermore, in order to develop an observer algorithm, e.g. a state estimator, it is desirable to obtain a model in a state-space description. Finally, it is convenient when the model parameters, such as length, masses, stiffness, can be tracked down to equivalent parameters in a known dummy model, which also favors modeling by a first-principles.

Available present-day crash occupant models aim in general at an extremely accurate and complete description of the occupant and its interaction with the vehicle. Their complexity makes them less suitable for control design. However, a lot of less complex models can be found in literature. Here, an overview of some low order vehicle occupant models for frontal impacts is presented. Given the objective of this study, the focus lies on an accurate description of thoracic injuries and belt behavior.

A huge amount of attempts has been made to describe the dynamics of an occupant ever since McHenry proposed one of the first very elementary models in 1963 [10]. An extensive but general overview is given in [11], [12], [13] in the eighties and more recently in [14], [15]. Simple occupant models have been described in [16], [17]. In these studies, the occupant is seated and subject to a frontal crash, but unrestrained. The two- or three-mass models in [8], [18], [19] of the thorax interacting with a seat-belt in frontal impacts are too elementary and lacks accuracy. In the threebody model presented in [20], the potential of fully adaptive restraint systems is presented, but the belt system is not modeled. In [21], a validated system model is provided, but, again, the belt system is not modeled which makes these models less useful in the present context.

\section{Approach and outline}

Existing occupant-restraint models are too complex, inaccurate or validated with outdated experimental data and hence not suited in the present context. The outlined modeling problem has led to an approach that is referred to as multi-fidelity modeling. Accurate and complex, high order models are employed to derive a number of less complex design models, dedicated to the control problem. The high order complex models have a high fidelity to real-life dummy crash tests and are therefore referred to as reference models. The design models have a lower fidelity to the real world. LTI models, which have to lowest fidelity, are derived from these design models and they may be used to develop the controllers.

The main contributions of this paper are as follows: (i) A manageable design model is derived that maps belt force to belt displacement and chest acceleration. It is accurate with respect to a reference model, incorporates physical parameters and has a low computational load, (ii) it is shown that the occupant motion during a frontal crash can be well described by linear models, (iii) the chest acceleration of the reference model is estimated by filtering of the belt displacement.

The plan of the paper is as follows. Section II describes the reference model used in this research. In section III, the design model is constructed and validated on accuracy and robustness. The derivation and analysis of the linear model, and the construction of the observer is given in section IV. Finally, section $\mathrm{V}$ shows the simulation results and the last section outlines the future work.

\section{THE REFERENCE MODEL}

\section{A. The PRISM model}

In this section, a description is given of the employed reference model, referred to as $\mathrm{G}_{\text {ref }}$. The family of dummies modeled in the Madymo [7], has proven to be versatile and accurate for different types of crashes and dummies [22]. Besides, the available coupling between Madymo and MATLAB/Simulink is of great advantage here. The system developed in Madymo by the PRISM project [6], is used as the reference model.

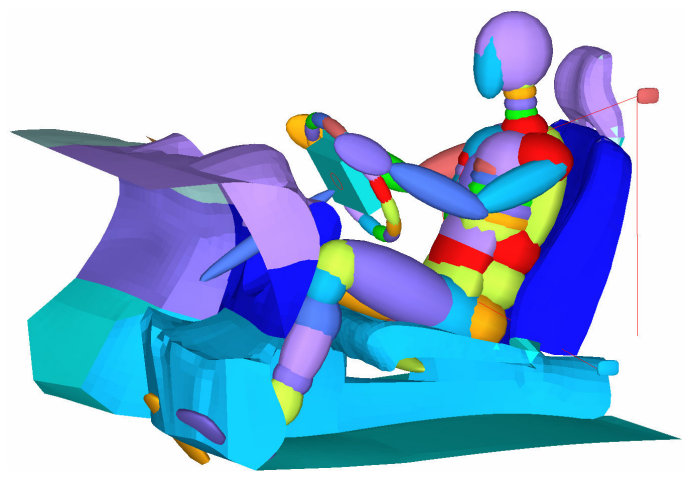

Fig. 1. Surface representation of the PRISM model

A surface representation of the vehicle interior and dummy is given in Fig. 1. The vehicle interior dimensions and contact characteristics are based on four super-mini vehicles and are modeled with both Finite Element (FE) and multi-body (MB) techniques. The three-point belt system is represented by seven segments with fixed attachment points on the occupant, although slip of the belt is allowed. The buckle pretensioner and airbag from the original PRISM model are removed in this study. The belt actuator is modeled as a force signal $F_{\text {belt }}$ that acts on a negligible mass connected to the belt at the retractor side. The $50^{\text {th }}$ percentile Hybrid III Madymo facet dummy model [7] is positioned in the compartment model. The dummy consists of 37 rigid bodies connected by 37 kinematic joints. Furthermore, a large number of possible contacts between dummy bodies and vehicle interior are defined. The crash pulse, i.e. the vehicle acceleration signal $a_{\mathrm{veh}}$, has been taken from experimental data of EuroNCAP 
frontal impact tests with the four super-mini vehicles. The standardized EuroNCAP frontal crash test is a frontal impact on a $40 \%$ offset deformable barrier at a speed of $15 \mathrm{~m} / \mathrm{s}$. The filtered vehicle acceleration signal $a_{\text {veh }}$ is shown in Fig. 2. It shows that the total crash time is around $140 \mathrm{~ms}$ and that the vehicle has a maximum deceleration of $370 \mathrm{~m} / \mathrm{s}^{2}$. In the simulations, the crash pulse is applied to the seated occupant as an external acceleration field.

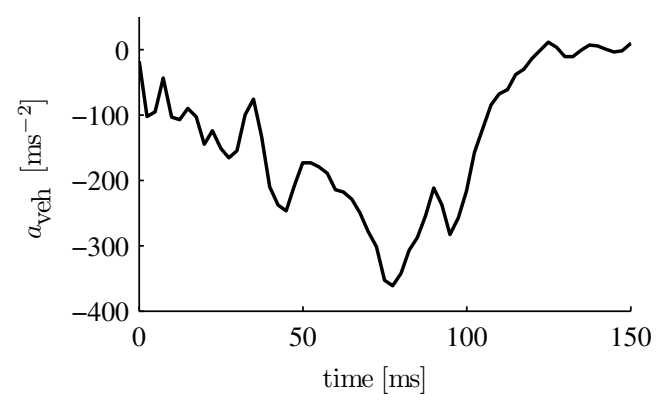

Fig. 2. The vehicle acceleration signal $a_{\mathrm{veh}}$

\section{B. Closed loop simulation}

As stated in Section I-D, the goal is to derive a low-order design model from this reference model. In analyzing the reference model, it is important to have the its behavior close to the desired controlled behavior. The desired behavior is defined as the optimal chest acceleration in terms of the injury criterium. To this end, a tracking control problem has been defined for the reference model, as sketched in Fig. 3.

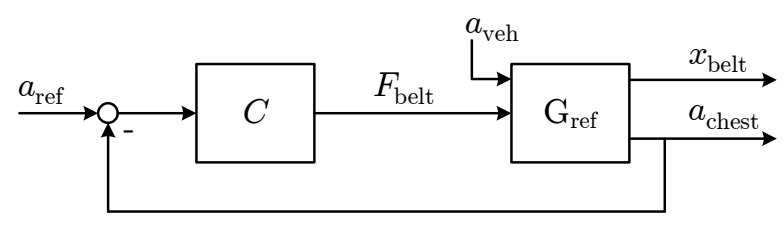

Fig. 3. The tracking problem in active restraint systems

In this layout, the crash pulse $a_{\text {veh }}$ acts as a disturbance on the system, and the $a_{\text {chest }}$ and $x_{\text {belt }}$ are the relevant outputs of the system. The belt displacement will be used as the observable output to estimate the chest acceleration, and hence both outputs have to included in the design model. The setpoint for the desired behavior of $a_{\text {chest }}$ is given by $a_{\text {ref. }}$ It is defined as an acceleration signal of which the peak acceleration is minimized. In the construction of $a_{\text {ref }}$, however, there are some constraints to fulfill. Firstly, the chest may not contact the vehicle interior during the crash. Secondly, the chest velocity $v_{\text {chest }}$ at the end of the crash should be zero. More details on the construction can be found in [4].

Although the aim of the study is to construct low-order design models that aid in controller and observer design, a controller is at this point already required. Since there is no knowledge on the model yet, a very simple ad-hoc controller is used. A (belt) force is used to control an acceleration, and it is therefore expected that an integrator with a proper gain would give stability, and sufficient low frequency gain for tracking performance [23]. The closed loop results with a controller $C(s)=5 \cdot 10^{5} / \mathrm{s}$ show that such a simple controller gives good performance in this specific scenario, see the middle figure in Fig. 4. The required control action $F_{\text {belt }}$ is shown in the top figure, and the belt displacement in the bottom figure.
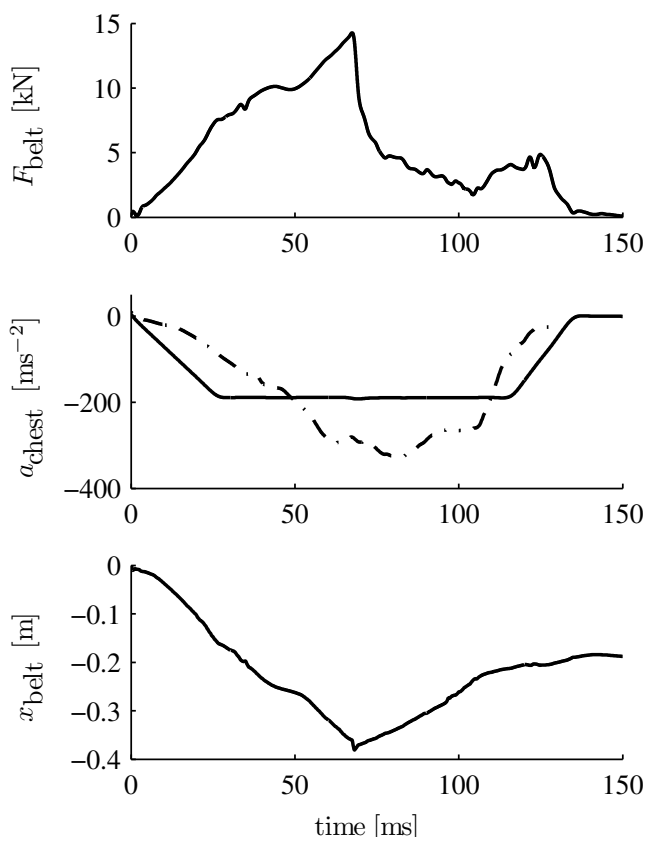

Fig. 4. Beltforce $F_{\text {belt }}$ (top), controlled (-) and uncontrolled (-.) chest acceleration $a_{\text {chest }}$ (middle) and $x_{\text {belt }}$ (bottom) of a closed loop simulation with the reference model

\section{The Design Model}

\section{A. Sensitivity analysis}

The design model $\mathrm{G}_{\text {design }}$ should be able to generate responses $a_{\text {chest }}$ and $x_{\text {belt }}$ that are in close agreement with the responses sketched in Fig. 4, given the obtained input $F_{\text {belt }}$ and disturbance $a_{\text {veh }}$. To identify the relevant elements in the reference model, a sensitivity analysis is performed. In this analysis, elements in the reference model are perturbed and it is analyzed how this affects the responses $a_{\text {chest }}$ and $x_{\text {belt }}$. These evaluations are carried out open loop, since the feedback controller would otherwise smooth out the perturbed outputs. When an element perturbation causes an output perturbation of more than $10 \%$, it is assumed that this element has a significant influence on the responses, and it is included in the design model. It should be mentioned, however, that conclusions of such an analysis only hold for the specific scenario, i.e. the crash pulse and belt force. A robustness analysis should indicate whether these parameters are also insignificant in other scenarios. The sensitivity analysis has primarily been performed for the joint characteristics, contact models and degrees of freedom. The result of the analysis has led to construction of the design model. Additionally, more insight has been gained in the 
dynamic behavior of an occupant interaction with a restraint system in frontal impact.

\section{B. Construction of the design model}

In frontal impacts, the vehicle occupant will primarily move in the symmetry plane of its body, i.e., rotations around the body's symmetry axis are small. The motion of the occupant could therefore be well described in two dimensions. The design model is constructed as follows. With the results of the sensitivity analysis, and by lumping both arms and both legs together, a set of 8 bodies represents the occupant and 1 body is used to represent the belt actuator body. The system has 11 degrees of freedom, and the locations of the joints are directly taken from the PRISM model. The locations and values of the centers of mass and moments of inertia of the (combined) bodies are derived from the PRISM model. The joints are modeled as kinematically ideal hinges with linear springs and dampers. Contacts between the bodies and the vehicle interior are described by means of Kelvin elements. The belt compliance is only taken into account in the belt segment between retractor and D-ring. The sensitivity analysis revealed that friction in the D-ring and buckle could not be ignored. The D-ring and buckle are modeled as a fixed, i.e. non-rotating, pulleys. Friction between belt and this pulley occurs when the two belt tension forces are not equal. The friction force $W$ in that case is given by [7]

$$
W=F_{2}\left(e^{\beta \varphi}-1\right)=F_{1}-F_{2},
$$

in which $\beta$ is a friction coefficient, $F_{2}$ the smallest tension force and $\varphi$ the wrapped angle. The structural layout of the design model is shown in Fig. 5.

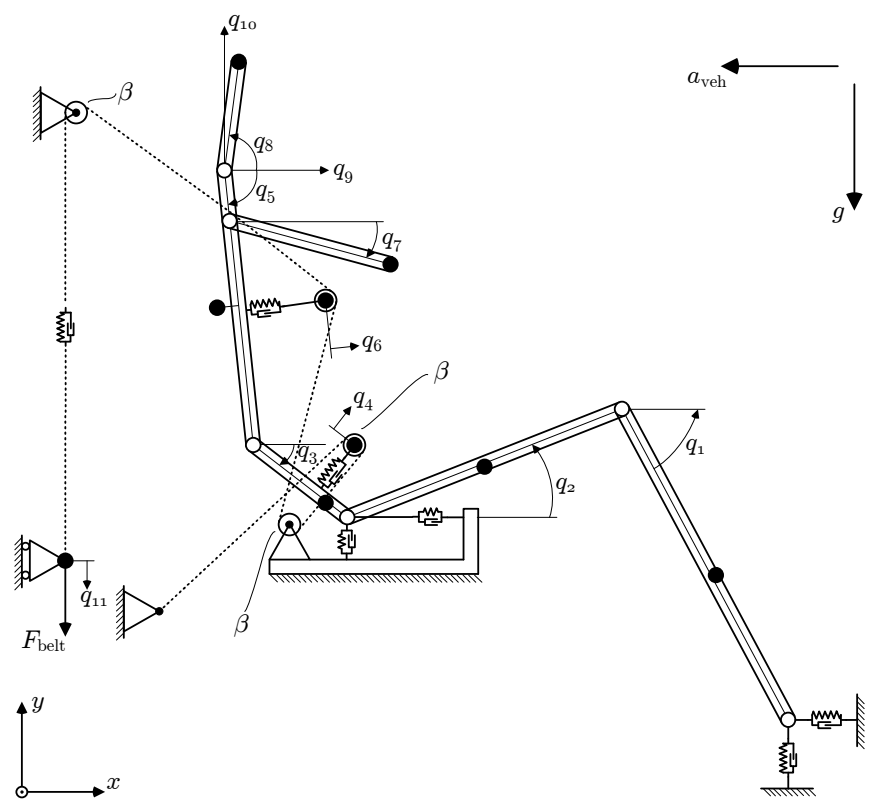

Fig. 5. Representation of the design model

A Lagrangian formulation is used to derive the set of differential equations that govern the dynamic behavior. The
Lagrangian procedure is computationally inefficient due to differentiations of the kinetic energy, but the derivation itself, however, is straightforward. For this system, 11 generalized coordinates are defined that completely describe the kinematics. With the generalized coordinate vector $q=$ $\left[\begin{array}{llll}q_{1} & q_{2} & \ldots & q_{11}\end{array}\right]^{T}$, the equations of motion can be derived from

$$
\frac{d}{d t} \frac{\partial \mathcal{L}}{\partial \dot{q}}-\frac{\partial \mathcal{L}}{\partial q}=Q^{\mathrm{nc}} \quad \text { with } \quad \mathcal{L}=T-V
$$

with $Q^{\text {nc }}$ the nonconservative generalized forces, $\mathcal{L}$ the Lagrangian and $T(\dot{q}, q)$ and $V(q)$ the total kinetic and potential energy respectively [24]. Further elaboration results in

$$
M(q) \ddot{q}=k(q, \dot{q})+Q^{\mathrm{nc}}(q, \dot{q}, u),
$$

with $M$ the mass matrix, $k$ the generalized Coriolis forces and $u$ the belt force $F_{\text {belt }}$.

\section{Simulation results}

The set of equations in (1) is derived entirely in symbolic form to allow optimization of the parameters. Many of the parameters in the reference model are uncertain or encrypted, so they can implemented directly in the design model. The RMS error between the responses of $\mathrm{G}_{\mathrm{ref}}$ and $\mathrm{G}_{\text {design }}$ is minimized for these uncertain parameters with an optimization algorithm. The simulation results are shown in Fig. 6. There exists a good agreement in chest accelerations, especially in the first $25 \mathrm{~ms}$. Also the belt displacement is well described by the design model.
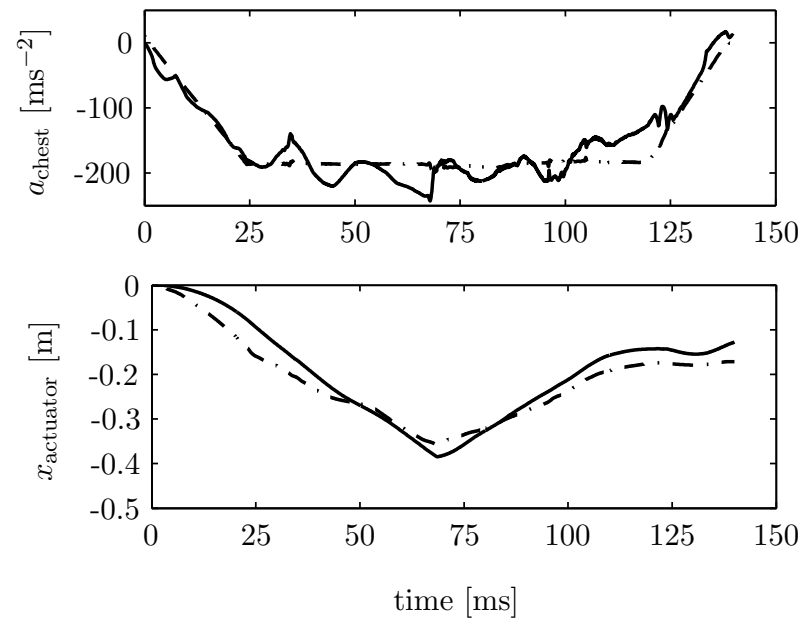

Fig. 6. Open loop results of the nonlinear design model, with the inputs $F_{\text {belt }}$ and $a_{\text {veh }}$ from the closed loop simulation with the truth model. The results from the truth model (dashed) are compared to the results from the design model (solid).

Animations have shown that the overall occupant behavior is very comparable to $\mathrm{G}_{\mathrm{ref}}$ behavior. It is therefore expected that the design model can also be used for different vehicle acceleration pulses, but this is not tested at this point. So no conclusions can be drawn about the robustness of the model. 


\section{THE OBSERVER DESIGN}

\section{A. Linearization of the design model}

With a proper, low-order design model, an observer can be designed. It is proposed to use a state estimator, and to this end, the design model is converted to a LTI state space model. The equations of motion of the design model are given in (1). They can be rewritten to yield the following set of nonlinear state-space equations

$$
\begin{aligned}
& \ddot{q}=f(q, \dot{q}, u, w) \\
& z=g(q, \dot{q}, u, w) \\
& y=h(q, \dot{q}, u, w),
\end{aligned}
$$

with $y=x_{\text {belt }}, z=a_{\text {chest }}$ and $w=a_{\text {veh. }}$. The positions and velocities vectors are stacked in a single state vector $x=\left[\begin{array}{cc}q^{T} & \dot{q}^{T}\end{array}\right]^{T}$. A first order Taylor expansion around $x^{*}=\left[q\left(\tau_{k}\right)^{T} 0^{T}\right]^{T}$ and $w^{*}=u^{*}=0$ leads to the following set of linearized equations

$$
\begin{aligned}
\Delta \dot{x} & =A \Delta x+B_{1} w+B_{2} u \\
z & =C_{1} \Delta x+D_{11} w+D_{12} u \\
y & =C_{2} \Delta x+D_{21} w+D_{22} u
\end{aligned}
$$

in which $\Delta x=x-x^{*}$. So the linearisation is performed for zero input and around different initial positions $q\left(t=\tau_{k}\right)$ with $\tau_{k}=10 k \mathrm{~ms}$ for $k=0, \ldots, 14$. Simulations with the linear model indicates that a linearization around $t=40$ ms yields the most accurate time responses. The transfer functions between inputs and outputs are defined as follows

$$
\left[\begin{array}{l}
z \\
y
\end{array}\right]=G(s)\left[\begin{array}{l}
w \\
u
\end{array}\right]=\left[\begin{array}{ll}
G_{11}(s) & G_{12}(s) \\
G_{21}(s) & G_{22}(s)
\end{array}\right]\left[\begin{array}{l}
w \\
u
\end{array}\right],
$$

The gains of the frequency response functions are shown in Fig. 7. As can be expected, $\mathrm{G}_{12}$ and $\mathrm{G}_{22}$ have a slope of 0 and -2 at high frequencies, since they map force to acceleration and position respectively. The open loop system $\mathrm{G}_{12}$ with the controller $C(s)$ from Section III is stable with a bandwidth of $837 \mathrm{~Hz}$, which indicates that this linear model is at least not incorrect, see Fig. 8.
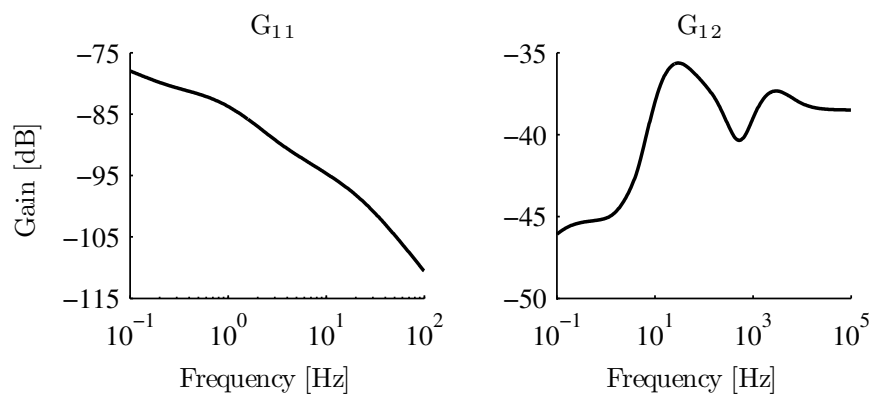

Fig. 7. Bode diagrams of LTI design model

\section{B. Observer design}

In the control system, the output $y$ is used to estimate the states $x$, and (part of ) these states are also controlled by $u$ to obtain a desired output $z$. It would therefore be preferable to balance the linear system in the observability and
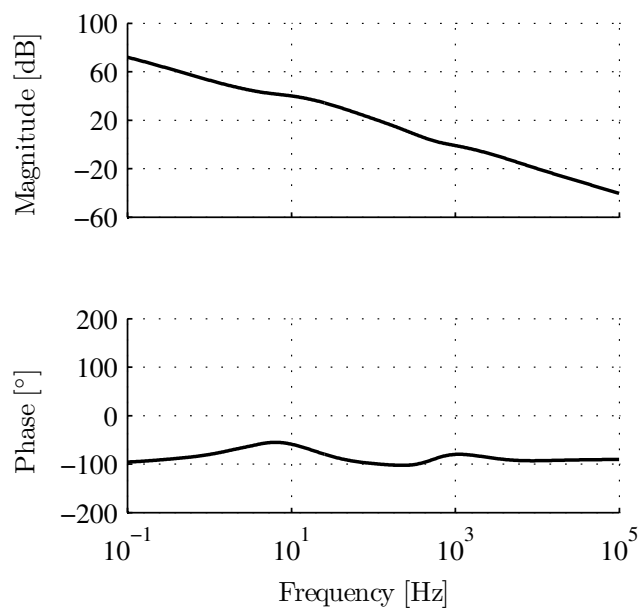

Fig. 8. Bode diagram of the open loop system with $\mathrm{G}_{12}$

controllability grammians. However, a state transformation is undesirable, since the nonlinear output equation in (2) can then not be used to predict the output $z$. For this reason, the observer is designed with the unbalanced system $\mathrm{G}_{22}$.

Analysis of the linear system shows that the pair $\left(A, C_{2}\right)$ is detectable. The singular values of the observability matrix of the pair $\left(A, C_{2}\right)$ indicate that 5 states transfer considerably more energy to the output than the remaining 17 states. This may result in some badly observable states. An ordinary state estimator can be constructed with a Kalman gain $K_{\mathrm{f}}$. Since the system is detectable, a Kalman gain $K_{\mathrm{f}}$ exists that renders $\left(A-K_{\mathrm{f}} C_{2}\right)$ stable [25]. With $D_{22}=0$, the state estimator $\mathrm{G}_{\text {estim }}$ admits the following structure

$$
\begin{aligned}
\Delta \dot{\hat{x}} & =A \Delta \hat{x}+B_{1} w+B_{2} u+K_{\mathrm{f}}\left(y-C_{2} \Delta \hat{x}-D_{21} w\right) \\
& =\left(A-K_{\mathrm{f}} C_{2}\right) \Delta \hat{x}+\left[\begin{array}{c}
B_{1}-K_{\mathrm{f}} D_{21} \\
B_{2} \\
K_{\mathrm{f}}
\end{array}\right]^{T}\left[\begin{array}{l}
w \\
u \\
y
\end{array}\right]
\end{aligned}
$$

Methods to calculate $K_{\mathrm{f}}$ can be found in standard textbooks, e.g., [25].

\section{RESUlts}

The state estimator system $\mathrm{G}_{\text {estim }}$ is applied to the nonlinear design model $\mathrm{G}_{\text {design }}$ as sketched in Fig. 9. The crash pulse $w$, observable belt displacement $y$ and belt force $u$ are inputs to the estimator model. The resulting estimate is in fact the deviation $\Delta x$ of the state, so $x^{*}$ has to be added to obtain the estimated state $\hat{x}=\left[\begin{array}{ll}\hat{q} & \dot{\hat{q}}\end{array}\right]^{T}$. With the nonlinear output state equation (2), the chest acceleration is estimated. Initial conditions for the state estimator deviated $20 \%$ from the true initial condition, $\Delta \hat{x}\left(t_{0}\right)=(1 \pm 0.2)\left(x\left(t_{0}\right)-x^{*}\right)$. The results of the estimated outputs are given in Fig. 10. They show fast convergence in the output error $(y-\hat{y})$ and slower convergence in $\left(z-z_{\text {nonlin }}\right)$, but the results are still good. Since the observer minimizes the error in the estimated output $y$ and not in $z$, the accuracy of $\hat{z}$ with respect to the truth model is entirely limited by the output equation $g(q, \dot{q})$ in (2). Therefore, the performance of the observer is best showed when it is applied to the design model. 


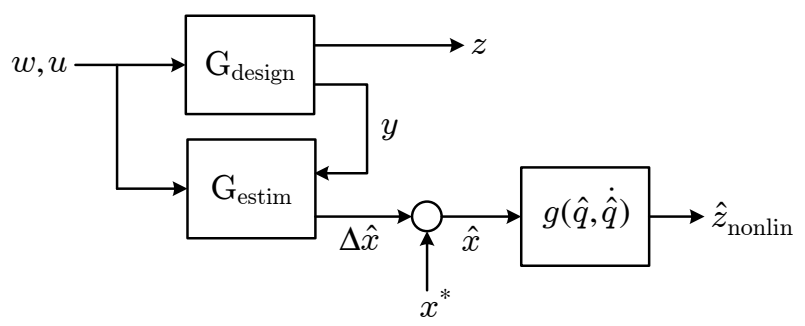

Fig. 9. Schematic representation of the observed system
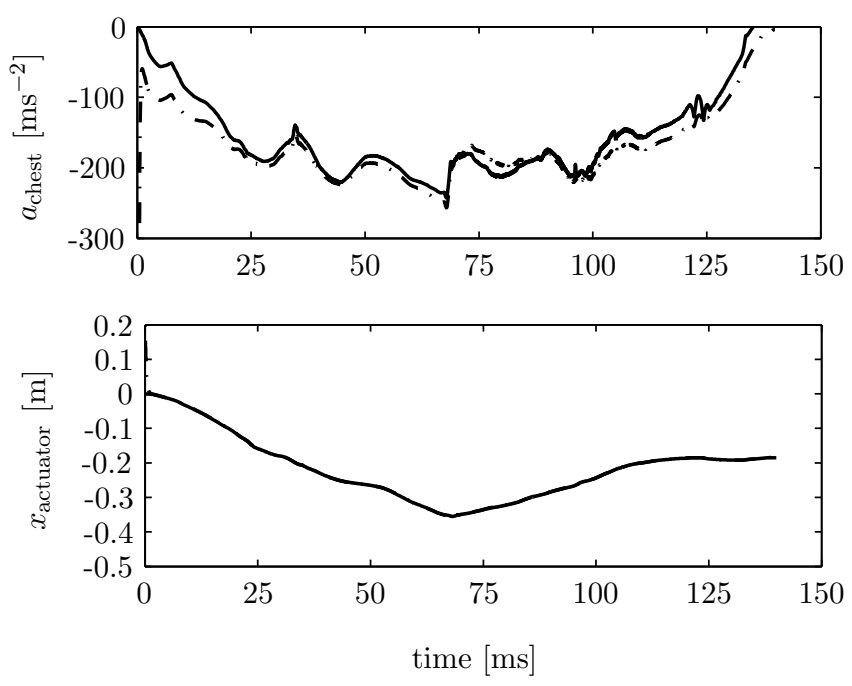

Fig. 10. Chest acceleration $a_{\text {chest }}$ (top) and belt displacement $x_{\text {belt }}$ (bottom) of the $\mathrm{G}_{\text {design }}$ model (solid) and $\mathrm{G}_{\text {estim }}$ (dashed)

\section{CONCLUSiOnS AND OUTLOOK}

In this paper, a first step towards the development real-time controlled restraint systems in passenger vehicles is made. It has been proposed that filtering of an observable output could help in the real-time estimation of biomechanical responses, a major issue in today's automotive safety engineering.

The objective of this study was to control the absolute chest acceleration in frontal impact by manipulating the belt force and filtering of the belt displacement at the outlet side. For the control design, specific and low order manageable models were required. A structured and systematic method has been presented to derive a design model from a complex, high order Madymo reference model. A sensitivity analysis has been conducted to identify relevant dynamics, and these elements are implemented in a design model. The linearized design model was used for a state estimator. This method of deriving a hierarchial structure of models with a different fidelity to the real world, is referred to as multi-fidelity modeling. The resulting state estimator was able to accurately predict the chest acceleration.

The proposed method in this paper to use an observer to estimate injury measures, is novel and might prove to be a promising tool in automotive safety engineering. In the near future, controllers will be added to the estimator system.

\section{REFERENCES}

[1] S. Thomas and D. Viano, "Dual depth patent," vol. Patent no. US6616177, no. Corporation, General Motors, Sep. 92003.

[2] H. Mueller and L. Burghard, "Smart airbag systems," SAE Technical Papers, no. 980558, 1998.

[3] J. Musiol, L. Norgan-Curtiss, and M. Wilkins, "Control and application of intelligent restraint systems," SAE Technical Papers, no. 971052 , 1997.

[4] R. J. Hesseling, "Active restraint systems; feedback control of occupant motion," Ph.D. dissertation, TU Eindhoven, 2004.

[5] J. Cooper, P. Lemmen, and C. v. Schie, "Effectiveness of real time control for active restraint systems in frontal crashes," in Airbag 2004. Karlsruhe, Germany: Frauenhofer Gesellschaft, 29th November - 1st December 2004, pp. 1-7, paper no. 8.

[6] M. Bosch-Rekveldt, J. Brandse, G. Couper, R. Morris, and M. Neale, "Development and application of generic restraint numerical models for parametric investigations of selected impact scenarios," PRISM, Tech. Rep. R6, R7, december 2005.

[7] TNO, MADYMO Manual. TNO MADYMO B.V., 2005, vol. 6.3.

[8] J. R. Crandall, Z. Cheng, and W. Pilkey, "Limiting performance of seat belt systems for the prevention of thoracic injuries," Journal of Automobile Engineering, vol. 214, no. 2, pp. 127-139, 2000.

[9] E. v. d. Eijnden and e. al., "Smart safety: System definition," TNO Automotive," internal report, November 172004.

[10] R. McHenry, "Analysis of the dynamics of automobile passengerrestraint systems," 7th Stapp Car Conference Proceedings, SAE, 1963.

[11] P. Prasad, "A overview of major occupant simulation models," $S A E$ Paper, vol. 840855, pp. 1-10, 1984.

[12] P. Prasad and C. Chou, "A review of mathematical occupant simulation models," Crashworthiness and occupant protection in transportation, pp. 95-112, 1989.

[13] R. Huston, "Crash victim simulation: Use of computer models," International Journal of Industrial Ergonomics, vol. 1, no. 4, pp. 285291, 1987.

[14] P. Prasad, "Occupant simulation models: experiment and practice," in Crashworthiness of transportation systems: structural impact and occupant protection, J. Ambrósio and M. Pereira, Eds. Dordrecht: Kluwer Academic Publishers, 1997, pp. 209-220.

[15] J. Wismans, R. Happee, and J. v. Dommelen, "Computational human body models," in Impact biomechanics: from fundamental insights to applications, 124th ed., ser. Solid mechanics and its applications, M. Gilchrist, Ed. Ireland: Springer, 2005, pp. 417-429.

[16] M. Batman, "A two dimensional car crash victim simulation," Annual international conference of the IEEE engineering in medicine and biology society, vol. 12, no. 5, pp. 2165-2166, 1990.

[17] C. Featherstone, N. Lieven, and M. Lowson, "Passenger simulation to determine safety limits during emergency decelerations," SAE Technical Papers, vol. 01, no. 1124, 2002.

[18] H. Katoh and R. Nakahama, "A study on the ride-down evaluation," 9 th international technical conference on experimental safety vehicles, 1982.

[19] M. Habib, "Active control of vehicle occupant's motion in front- and rearend collisions," SAE Paper, vol. 01, no. 3430, 2001.

[20] T. Paulitz, D. Blackketter, and K. Rink, "Constant force restraints for frontal collisions," Proceedings of the Institution of Mechanical Engineers, Part D: Journal of Automobile Engineering, vol. 220, no. 9, pp. 1177-1189, 2006, doi:10.1243/09544070JAUTO306.

[21] T. Gordon and R. Hopkins, "Parametric identification of multibody models for crash victim simulation," Multibody System Dynamics, vol. 1, pp. 85-112, 1997.

[22] J. Ambrósio and M. Silva, "Multibody dynamics approaches for biomechanical modeling in human impact applications," in Impact biomechanics: from fundamental insights to applications, 124th ed., ser. Solid mechanics and its applications, M. Gilchrist, Ed. Ireland: Springer, 2005, pp. 61-80.

[23] S. Skogestad and I. Postlethwaite, Multivariable Feedback Control, 2nd ed. West Sussex, England: John Wiley \& Sons Ltd, 2005.

[24] B. d. Kraker and D. v. Campen, Mechanical vibrations. Eindhoven: Technische Universiteit Eindhoven, 2001.

[25] K. Zhou, J. Doyle, and K. Glover, Robust and optimal control. New Jersey: Prentice-Hall, 1996. 